\title{
Molecular and Biological Characterization of a Vaccine - Derived Avian Avulavirus Type 1 Isolated from an Unvaccinated Goose
}

\author{
B. Deepthi ${ }^{*}$, D. Ratnamma ${ }^{2}$, R. N. Ramani Pushpa ${ }^{1}$, Shrikrishna Isloor $^{2}$, \\ B. M. Veeregowda ${ }^{2}$ and M. L. Satyanarayana ${ }^{3}$ \\ ${ }^{1}$ Department of Veterinary Microbiology, NTR College of Veterinary Science, \\ Gannavaram, Andhra Pradesh, India, 521102 \\ ${ }^{2}$ Department of Veterinary Microbiology, ${ }^{3}$ Department of Veterinary Pathology, Veterinary \\ College, Bangalore, India, 560032 \\ *Corresponding author
}

\section{A B S T R A C T}

\section{Keywords}

Avian avulavirus, Waterfowl, Fusion protein,

Pathogenicity, Cytokines

\section{Article Info}

Accepted:

04 August 2020

Available Online:

10 September 2020
ND is one of the most devastating diseases of the poultry industry. The disease was categorized as 'notifiable' owing to the immense economic losses caused to the poultry farmers. Wide host range is one major limiting factor in controlling the disease. While chicken, turkeys, doves, pigeons are highly susceptible, waterfowls such as ducks and geese are less susceptible and considered as natural reservoirs for lentogenic AAvV-1. We isolated an AAvV-1 strain from a goose raised in a mixed species poultry farm. Full length fusion gene sequence confirmed that the isolate belongs to genotype II of class II AAvV-1. Phylogenetic studies grouped the isolate with vaccine strain, Komarov. Twenty one day old chicken inoculated with this isolate were apparently healthy without any clinical signs. Minimal upregulation of proinflammatory, chemokine and apoptic cytokine levels was observed in the spleen of infected chicken. This study paved way for isolation of a low pathogenic strain of $\mathrm{AAvV}-1$ from an apparently healthy water fowl. Further research is needed to evaluate the isolate as a vaccine candidate.

\section{Introduction}

Outbreaks of Newcastle disease (ND) are very common around the world resulting in serious economic losses to the poultry industry. World organization for animal health has recognized ND as "notifiable" (Dimitrov et al., 2016). Broad host spectrum, multiple genotypes and inadequate vaccination protocols compounded the nature of the disease, especially in the third world countries. ND is caused by Avian Avula virus -1 (AAvV-1, previously Newcastle disease virus). AAvV-1 belongs to genus Avian orthoavulavirus 1 (AOAV-1) within the subfamily Avulavirinae of the family Paramyxoviridae (ICTV, 2019). AAvV-1 cause infections in a wide range of domestic and wild birds worldwide. As many as 241 species from 27 orders of the avian family are reported to be susceptible to ND (Kaleta and Baldauf, 1988). AAvV-1 is a single-stranded, 
negative-sense, non-segmented and enveloped RNA virus with genome length of $15.2 \mathrm{~kb}$. The genome of AAvV-1 consists of six genes which encode at least seven proteins: nucleoprotein (NP), phosphoprotein (P), matrix protein $(\mathrm{M})$, fusion protein $(\mathrm{F})$, hemagglutinin-neuraminidase (HN), RNAdependent RNA polymerase or large protein (L), and the $\mathrm{V}$ protein produced through editing of the phosphoprotein mRNA (Alexander and Senne, 2008). Fusion protein cleavage site (FPCS) is one of the most important virulence factor which distinguishes an isolate to be lentogenic or velogenic (OIE, 2012). Further, based on the full - length $\mathrm{F}$ gene sequences, AAvV-1 has been classified into two major classes, I and II. All the avirulent isolates were classified under Class I, which includes a single genotype with three subgenotypes. Class II contains most of the virulent viruses circulating worldwide, classified into atleast 21 genotypes with multiple subgenotypes (Dimitrov et al., 2019) and this diversity continues to increase as the surveillance studies improves.

Wild aquatic birds are thought to be the natural reservoirs of NDV's of both classes, but they predominantly harbor lentogenic strains (Alexander, 2000). Ayala et al., 2016 demonstrated repeated isolation of vaccinederived Newcastle disease viruses from different species of wild birds across four continents from 1997 through 2014 and these viruses corresponded to Lasota and Hitchner B1. Moreover, Shengqing et al., 2002 demonstrated the potential of few lentogenic strains to become velogenic after transmission and circulation within the poultry population. Paucity of information still exists regarding the epidemiological relationships of NDV's circulating in wild aquatic birds.

Here we report natural occurrence of AAvV-1 in an unvaacinated, apparently healthy goose raised in a multi species poultry farm. The $\mathrm{AAvV}-1$ isolate was proven to be lentogenic and genetically similar to vaccine strains. The transmissibility of goose-originated NDV to chickens was also evaluated in this investigation. The continuous expansion of the poultry industry, coupled with the mass employment of live virus vaccines may contribute to the probability of spillover of vaccines (Devlin et al., 2016).

\section{Materials and Methods}

\section{Virus isolation and confirmation}

This work was carried out as a part of active ND surveillance conducted in a multi species poultry farm located in Hyderabad, Telangana, India. The poultry farm comprised of chicken, ducks, geese, turkeys and emu birds. Regular vaccinations were being done only in the chicken and the other birds were never vaccinated. Outbreaks of ND were recorded in chicken despite vaccination during the previous year of this study. For the present study, cloacal swabs were collected from geese $(n=15)$ present in the flock. The birds were apparently healthy showing no symptoms of ill- health at the time of sample collection. The samples were processed following standard protocols of virus isolation as specified in Terrestrial manual of OIE (OIE, 2012). Samples were inoculated into 9day-old embryonated chicken eggs (ECE) through allantoic route. The eggs were incubated at $37^{\circ} \mathrm{C}$, checked for mortality every $12 \mathrm{~h}$ until the embryos died or for a maximum period of $120 \mathrm{~h}$, whichever was earlier. The dead embryos were chilled at $4^{\circ} \mathrm{C}$ overnight for collection of amnio allantoic fluid (AAF). Each sample was passaged blindly thrice before considering it as negative. The collected AAF was tested for Hemagglutination activity (HA) as described in the OIE manual (OIE, 2012). The presence of AAvV-1 in allantoic fluid was then 
confirmed by hemagglutination inhibition (HI) test using polyclonal serum raised against LaSota (OIE, 2012).

\section{Mean death time (MDT) and Intracerebral pathogenicity index (ICPI)}

MDT in nine- day old embryonated chicken eggs and ICPI in day- old chicks were conducted according to OIE recommendations (OIE, 2012) to find out the pathogenicity of the isolate.

\section{Molecular characterization of the isolates}

Viral RNA was extracted from the allantoic fluid using TRIzol LS reagent (Genei, Bangalore). iScript TM cDNA synthesis kit (Biorad, USA) was used for synthesis of first strand cDNA using random hexamers. Presence of virus was confirmed by RT-PCR using primers targeting FPCS of fusion gene (Nantha Kumar et al., 2000). Complete fusion gene was amplified by primers designed by us using Primer 3 (Untergasser et al., 2012) and were validated using Oligo analyzer software v2.1. The details of primers are provided in Table 1. Amplified sequence was used for phylogenetic analysis and genotype determination. Services of commercial sequencing centre (Barcode Biosciences, India) were utilized for obtaining the sequence of amplified gene.

\section{Genotype analysis}

The sequence data of the isolate was subjected to blast analysis with the help of NCBI BLAST tool (https:// blast.ncbi.nlm.nih.gov/Blast.cgi) and compared with the AAvV-1 sequences available in GenBank. Phylogenetic analysis based on 36 nucleotide sequences of complete fusion gene of $\mathrm{AAvV}-1$ group available in public databases was performed in MEGA $\mathrm{X}$ software by maximum likelihood method by bootstrapping with 1000 replications based on the Tamura-Nei model (Tamura \& Nei, 1993). Initial tree(s) for the heuristic search were obtained automatically by applying Neighbor-Join and BioNJ algorithms to a matrix of pairwise distances estimated using the Maximum Composite Likelihood (MCL) approach, and then selecting the topology with superior log likelihood value. The maximum likelihood method based on the General Time Reversible (GTR) model with a discrete gamma distribution (five categories $[+\mathrm{G}]$ ) was utilized for the tree. All positions containing gaps and missing data were eliminated. There were a total of 1662 positions in the final dataset. The tree with the highest log likelihood (-12664.74) is shown. The evolutionary relationship between the geese isolate and 36 viruses belonging to class I AAvV-1 were estimated by calculating the number of base differences per site from averaging over all sequence pairs between groups using MEGA X (Kumar et al., 2018). Details of the accession numbers used for phylogenetic analysis were mentioned in the supplementary material.

\section{In vitro and $I n$ vivo responses to virus infection}

In vitro responses to virus infection were studied in CEF monolayers prepared from embryonated eggs as per the standard protocol described by Freshney (2000). The isolate was propagated in these monolayers to study the cytopathic changes induced by the virus.

Invivo responses to virus infection were studied by experimental infection conducted in chicken. Three- week old broiler chicks (Hiline breed) free of maternal antibodies were obtained from Srinivasa Hatcheries Ltd., Gannavaram. A total number of twenty one broiler chicks were split into 3 groups viz., uninfected control group $(n=7)$, infected $(n=7)$ 
and in-contact group $(\mathrm{n}=7)$. Infected and contact group were placed in nearby cages where as the control group was placed in another room far away from the other two groups. In- contact group was included with the main objective of assessing the risk of transmission from infected to non infected birds. Birds were maintained in cages and provided with un-medicated feed (Layer chick granules) and water ad libitum. Birds in infected group were inoculated with a single dose of $100 \mu \mathrm{l} \quad 10^{5} \mathrm{EID}_{50} / 0.1 \mathrm{ml}$ by subcutaneous route and were observed regularly for clinical signs and mortality. Control birds were inoculated with $0.1 \mathrm{ml}$ of PBS as placebo. One bird each was sacrificed on day 1, 3 and 5 PI. Spleen was collected in RNA later® (Sigma), for evaluating cytokine responses and tissues viz., spleen, intestines, trachea, lung, kidney, liver and heart were collected into $10 \%$ neutral buffered formalin for histopathology. Necropsies were performed on the dead birds to examine for gross lesions. The experiment was carried out twice.

\section{RNA extraction and cDNA from spleen tissue}

Total RNA was extracted from splenocytes as described previously. RNA at a minimum concentration of $1 \mu \mathrm{g}$ was used for reverse transcription using random hexamers and iScript ${ }^{\mathrm{TM}}$ cDNA synthesis kit (Biorad, USA). cDNA samples were initially confirmed for the presence of NDV in spleen tissue by RTPCR for Matrix (M) gene. Primer sequences used for amplification of $\mathrm{M}$ gene and cytokine expression were as described by Ranjani et al., 2018.

\section{Relative cytokine expression in infected spleen by quantitative RT-PCR}

Relative changes in RNA expression of proinflammatory cytokine genes (TNF- $\alpha$, IL- $1 \beta$ and IL-6), chemokine (IL-8) and apoptotic gene (Cas-8) and IL-10, an anti inflammatory cytokine and $\beta$ - actin for infected and mockinfected controls were measured as changes in SYBR green fluorescence after amplification with specific primer sets. Reactions were carried out in triplicate in $20 \mu 1$ volume using TB Green ${ }^{\circledR}$ Premix Ex Taq ${ }^{\text {TM }}$ II (Tli RNaseH Plus) TaKaRa (RR820A).

Amplification and detection of specific products were performed using the StepOnePlus TM Real-time PCR system (Applied Biosystems, USA) with the following cycle conditions: one cycle at $95^{\circ} \mathrm{C}$ for $3 \mathrm{~min}, 40$ cycles at $95^{\circ} \mathrm{C}$ for $5 \mathrm{sec}, 58^{\circ} \mathrm{C}$ for $15 \mathrm{sec}$ and $60^{\circ} \mathrm{C}$ for $30 \mathrm{sec}$. Relative changes in gene expression were calculated using double delta Ct method (Pflaffl, 2001). Average $\mathrm{Ct}$ values of infected samples were corrected to the average $\mathrm{Ct}$ of mock- infected control for each gene of interest and the endogenous control ( $\beta$ - actin). Relative gene expression was also compared using student $t$ test. $p$ values less than or equal to 0.05 were considered significant changes in gene expression.

\section{Results and Discussion}

\section{Virus isolation and confirmation}

In this study, we obtained an $\mathrm{AAvV}-1$ isolate (AAvV-1/ Geese/ Hyd/ 2018,) from an apparently healthy goose at an organized poultry farm with multiple avian species. The virus was isolated during second passage in 9to 11- day old embryonated chicken eggs. Death of the embryos was not observed even after $120 \mathrm{~h}$ and the harvested embryos did not exhibit any specific lesions. Allantoic fluid had a haemagglutination titre of 128 per 50 $\mu 1$. HI titre with polyclonal chicken antiserum to LaSota was 1:256 thus confirming the isolate as $\mathrm{AAvV}-1$. In addition, Mean death time score in 9-11 day old embryonated 
chicken eggs was $>120 \mathrm{~h}$ and ICPI score in day- old chicks was 0.2 , suggesting that the isolate was avirulent to chicken.

\section{Molecular and phylogenetic analysis}

The F gene was amplified by RT-PCR using consensus primers. The product size of the $\mathrm{F}$ gene was 1662 bp in length. The purified product was sequenced and submitted to GenBank and the accession number MT420247 was obtained. The current NDV classification criteria for genotype and subgenotype identification were followed in this study (Dimitrov et al., 2019). The goose isolate clustered with class II, genotype II AAvV-1 viruses which includes commonly used vaccine strains (Fig. 1).

Table.1 Details of primers designed for the study

\begin{tabular}{|l|l|c|c|}
\hline First set & \multicolumn{1}{|c|}{ Primer sequences (5'-3') } & Ta(oC) & Product size (bp) \\
\hline Second set & $\begin{array}{l}\text { GGTACCTCTACTAAGCTGG } \\
\text { CTGCCACTGCTAGTTGAGATAATCC }\end{array}$ & 56 & 758 \\
& $\begin{array}{l}\text { CCTTGGTGAATCTATCCGAAG } \\
\text { CCCAAGCTCAGTTGAGATATC }\end{array}$ & 56 & 1123 \\
\hline Third set & $\begin{array}{l}\text { TAGGCGGGATAACTTTAAGG } \\
\text { GTCGGTATGCCTACAAGATC }\end{array}$ & 56 & 765 \\
\hline
\end{tabular}

Fig.1 Molecular Phylogenetic analysis based on fusion gene sequences of AAvV-1 isolates of genotype II class II by Maximum Likelihood method -The evolutionary history was inferred by using the Maximum Likelihood method based on the Tamura-Nei model [1]. The tree with the highest log likelihood (-12664.74) is shown. Initial tree(s) for the heuristic search were obtained automatically by applying Neighbor-Join and BioNJ algorithms to a matrix of pairwise distances estimated using the Maximum Composite Likelihood (MCL) approach, and then selecting the topology with superior log likelihood value. The analysis involved 37 nucleotide sequences. All positions containing gaps and missing data were eliminated. There were a total of 1662 positions in the final dataset. Evolutionary analyses were conducted in MEGAX

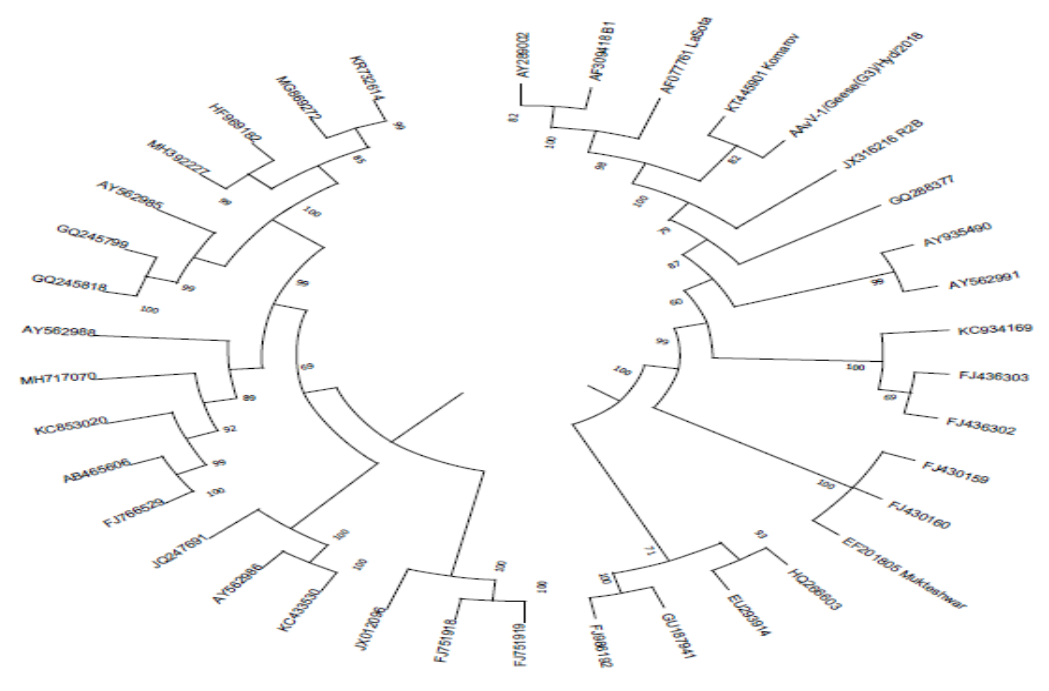


Fig.2 Cytopathic changes viz. rounding of fibroblasts, formation of syncytia and cytoplasmic process observed in the infected chicken embryo fibroblast monolayers
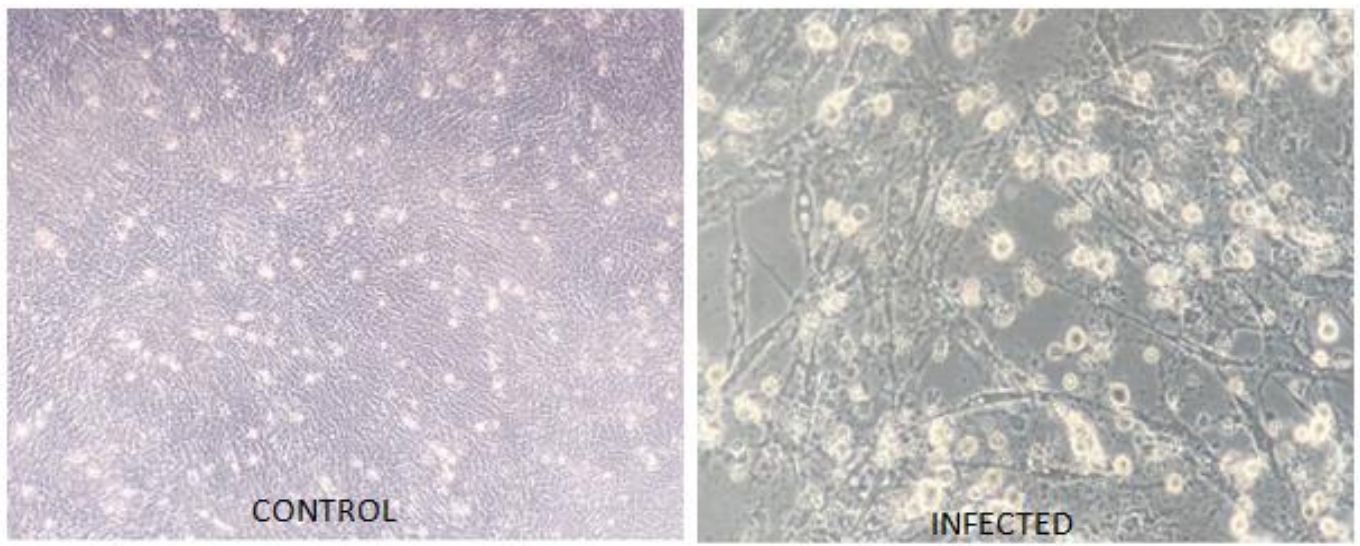

Fig.3 Expression of cytokine mRNA levels in spleen of infected chicken measured at 1, 3 and $5 \mathrm{dpi}$

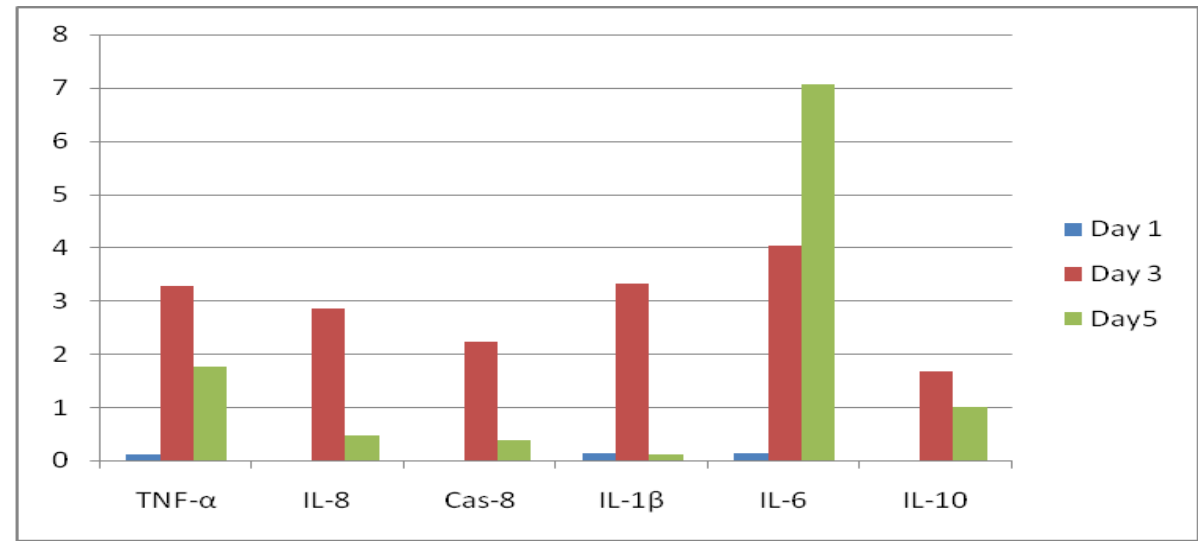

In vitro and In vivo responses to virus infection

Infected CEF monolayers exhibited cytopathic changes typical for Newcastle disease virus viz., increased cellular granularity, rounding, vacoulation and syncytia formation (Figure 1). Slight granulation was observed after $48 \mathrm{~h}$ post inoculation which later progressed. Infected cells enlarged with intracytoplasmic vacoulation. Syncytia formation was observed $72 \mathrm{~h}$ post inoculation (Fig. 2).

Infected and control group birds were active and apparently healthy all through the study.
Neither mortality nor clinical signs were observed indicating absence of virus infection. Additionally, mortality and clinical signs were not observed in the contact group too. Tissues collected on day 1, 3 and 5 post inoculation such as spleen, intestines, lungs, kidneys, trachea and heart did not show any pathological lesions.

Relative expression of cytokine genes in response to AAvV-1 (Goose isolate) are depicted as bar diagram (Fig. 3). The basal cytokine mRNA level is considered as onefold (Li et al., 2007). Hence, a statistically significant increase above one- fold is regarded as upregulated $(\mathrm{p}<0.05)$. The 
specificity of the cytokine genes was initially confirmed by the melting curve. Upregulation of TNF- $\alpha$, IL-1 $\beta$, Cas-8, IL-10, IL-6 and IL-8 was minimal (less than 10 folds) was noted on day 1,3 and 5 post infection and this correlated with apparently healthy chicken.

$\mathrm{NDV}$, now called as AAvV-1, is endemic to many countries resulting in heavy mortality thus incurring huge losses to poultry farmers. In mixed poultry farming, there are opportunities for transmission of viruses between chicken and other avian species which are normally refractory to such infections.

A lentogenic ND isolate named AAvV-1/ Goose/ Hyd /2018 obtained from a clinically healthy geese flock with no history of vaccination against ND was used in this study. Based on MDT, ICPI and FPCS sequence, the virus could be classified as velogenic. Analysis of the complete fusion protein clustered the emu isolate with subgenotype XIII 2.2 viruses of class II NDV according to the updated classification of NDV (Dimitrov et al., 2019). cds of the fusion gene comprised of 1659 nucleotides coding for 553 amino acids just like any other $\mathrm{AAvV}-1$ isolate. The amino acid sequence of fusion protein cleavage site was ${ }^{112} \mathrm{R}-\mathrm{R}-\mathrm{K}-\mathrm{K}$ $\mathrm{R}-\mathrm{F}^{117}$ which matched with other mesogenic isolates like Komarov (Genbank ID KT445901). F gene of NDV determines the virulence (Nagai et al., 1976; Peeters, 1999) and the amino acid sequence of FPCS between positions 112-117 serve as a promising tool for pathotyping. A pair of basic aminoacids, Lysine $(\mathrm{K})$ and/ or Arginine (R) at positions 116 and 115, with Arginine (R) at 113 position and phenylalanine $(\mathrm{F})$ residue at position 117 , is an indication of mesogenic or velogenic strains.

In the present study, the isolate had Arginine (R) at 113 position, Lysine (K) at 115 position, Arginine (R) at 116 position and phenylalanine $(\mathrm{F})$ residue at 117 position confirming its status as virulent. But these findings are not in agreement with the MDT $(>120 \mathrm{~h})$ and ICPI (0.2) values which indicate avirulent nature. Based on the phlogenetic tree constructed by neighbor joining (NJ) algorithm with a bootstrap value of 1000 along with pairwise distances, the isolate clustered with mesogenic strain, Komarov (K). Both these isolates have a common node with another group consisting of Lasota, B1 and AY289002.

Based on the sequence identity matrix, it is clear that the isolate obtained in this study was $100 \%$ similar at FPCS region to the mesogenic strain, Komarov. The cleavage site was unique and suggestive of a moderately virulent virus, although the ICPI value was 0.2 indicative of lentogenic nature.

Almubarak, 2019 noticed a similar incongruence between FPCS and ICPI, where the AAvV-1 strains isolated from chicken belonged to genotype II with the lentogenic motif ${ }^{112}$ GRQGRL ${ }^{117}$ at the FPCS while the ICPI and MDT values indicated velogenic nature. Tan et al., 2008 also isolated three AAvV-1 strains with FPCS $\left({ }^{113} \mathrm{G}-\mathrm{R}-\mathrm{Q}-\mathrm{G}-\mathrm{R}-\right.$ $\mathrm{L}^{117}$ ) corresponding to lentogenic strains while ICPI and IVPI showed that the isolates are velogenic in nature. Such incongruence between FPCS and the pathogenicity tests is due to recombination between virulent strains and vaccine- derived viruses resulting in deduced FPCS (Kattenbelt et al., 2006).

To establish this fact, in vivo studies were taken up to determine whether the strain could initiate clinical disease in chicken. Studies pertaining to in vivo responses of the host during infection in relation to cytokine expression are still lacking. Most of the early immune response to any pathogen is dictated by cytokines. As evidenced by several 
studies, NDV replicates in lymphocytes and macrophages and during early stages of the infection, viral antigens and genomic RNA are mostly found in tissue macrophages (Kommers et al., 2002; Cornax et al., 2013). These cells secrete cytokines in response to infection. The spleen hosts all major types of mononuclear phagocytes, including macrophages, dendritic cells and monocytes. Hence, spleen will be the best choice to study up/ down regulation of cytokines during infection. At different time points of infection, spleens were collected from chicken infected with goose isolate and relative expression of cytokines was analysed by quantitative PCR (qPCR). Minimal upregulation of pro inflammatory and apoptic gene mRNA levels is observed in this study which also correlated with the absence of clinical signs and histopathological lesions typical for ND.

From an epidemiological view point, Geese present a unique feature of free ranging, aquatic nature favouring contact with wild birds which increase the risk of exposure to virus (Alexander, 2000). Ducks and geese are usually considered as asymptomatic carriers though few authors reported incidences of mild infection in these species. Though these species are not vaccinated routinely, chicken are usually vaccinated with genotype II strains. All these conditions may contribute to circulation of genotype II strains in water fowls without causing infection. Hence, rearing facilities for commercial poultry and water fowls should be separated.

In the wake of present findings, it is quintessential to expand epidemiological and molecular investigations not just confining to commercial poultry, but need to include all the domesticated avian species. Novel vaccination regimens have to be evolved to suit every domesticated bird.

\section{Acknowledgements}

The authors thank Sri Venkateswara Veterinary University (SVVU), Tirupati, India for providing necessary facilities for the first author to carry out and complete her $\mathrm{PhD}$ thesis research work.

\section{References}

Alexander DJ, Senne DA(2008)Diseases of poultry. Blackwell, Ames, IA. Alexander, D.J., 2000. Newcastle disease and other avian paramyxoviruses. Revue Scientifique et Technique-Office International des Epizooties, 19(2), pp.443-455.

Almubarak, A.I., 2019. Molecular and biological characterization of some circulating strains of Newcastle disease virus in broiler chickens from Eastern Saudi Arabia in 2012-2014. Veterinary World, 12(10), p.1668.

Ayala AJ, Dimitrov KM, Becker CR, Goraichuk IV, Arns CW, Bolotin VI, Ferreira HL, Gerilovych AP, Goujgoulova GV, Martini MC, Muzyka DV,Orsi MA, Scagion GP, Silva RK, Solodiankin OS, Stegniy BT, Miller PJ and Afonso CL (2016) Presence of vaccine-derived Newcastle disease viruses inwild birds. PLoS One 11, e0162484.

Cornax, I., Diel, D.G., Rue, C.A., Estevez, C., $\mathrm{Yu}$, Q., Miller, P.J. and Afonso, C.L., 2013. Newcastle disease virus fusion and haemagglutinin-neuraminidase proteins contribute to its macrophage host range. The Journal of general virology, 94(Pt 6), p.1189.

Devlin, J.M., Vaz, P.K., Coppo, M.J. and Browning, G.F., 2016. Impacts of poultry vaccination on viruses of wild bird. Current opinion in virology, 19, pp.23-29.

Dimitrov KM, Abolnik C, Afonso CL, Albina E, Bahl J, Berg M, Briand FX, Brown IH, Choi KS, Chvala I and Diel DG (2019) 
Updated unified phylogenetic classification system and revised nomenclature for Newcastle disease virus. Infection, Genetics and Evolution74:103917.

Dimitrov KM, Ramey AM, Qiu X, Bahl J, Afonso CL (2016) Temporal, geographic, and host distribution of avian paramyxovirus 1 (Newcastle disease virus). Infect Genet Evol 39:22-34.

Hay, R.J. and Freshney, R.I., 2000. Animal cell culture: a practical approach. Freshney $R I, 6$.

Kaleta, E.F. and Baldauf, C., 1988. Newcastle disease in free-living and pet birds. In Newcastle disease (pp. 197-246). Springer, Boston, MA.

Kattenbelt JA, Stevens MP, Gould AR. Sequence variation in the Newcastle disease virus genome. Virus Res. 2006; 116(1-2):168-84.

Kommers, G.D., King, D.J., Seal, B.S. and Brown, C.C., 2001. Virulence of pigeonorigin Newcastle disease virus isolates for domestic chickens. Avian diseases, pp.906-921.

Li, Y.P., Handberg, K.J., Juul-Madsen, H.R., Zhang, M.F. and Jørgensen, P.H. (2007). Transcriptional profiles of chicken embryo cell cultures following infection with infectious bursal disease virus. Arch. Virol. 152: 463-478.

Nanthakumar, T., Kataria, R.S., Tiwari, A.K., Butchaiah, G. and Kataria, J.M., 2000. Pathotyping of Newcastle disease viruses by RT-PCR and restriction enzyme analysis. Veterinary Research Communications, 24(4), pp.275-286.

OIE, 2012. Newcastle disease. Manual of diagnostic tests and vaccines for terrestrial animals: mammals, birds and bees. Biological Standards Commission. World Organisation for Animal Health, Paris, France, pp. 555-574.

Rajasekaran, R., Kirubaharan, J.J., Vidhya, M., Shilpa, P. and Chandran, N., 2019. Proinflammatory cytokine and apoptotic gene mRNA levels against lentogenic and velogenic Newcastle disease virus pathotypes in in-vivo and in-vitro biological systems. Indian Journal of Animal Research, 53(4), pp.515-522.

Shengqing, Y., Kishida, N., Ito, H., Kida, H., Otsuki, K., Kawaoka, Y. and Ito, T., 2002. Generation of velogenic Newcastle disease viruses from a nonpathogenic waterfowl isolate by passaging in chickens. Virology, 301(2), pp.206-211.

Tamura, K. and Nei, M., 1993. Estimation of the number of nucleotide substitutions in the control region of mitochondrial DNA in humans and chimpanzees. Molecular biology and evolution, 10(3), pp.512-526.

Tan, L.T., Xu, H.Y., Wang, Y.L., Qin, Z.M., Sun, L., Liu, W.J. and Cui, Z.Z., 2008. Molecular characterization of three new virulent Newcastle disease virus variants isolated in China. Journal of Clinical Microbiology, 46(2), pp.750-753.

Taxonomy, I.V., 2018. Release. 2019. International committee on taxonomy of viruses.v/msw054.

Untergasser, A., Cutcutache, I., Koressaar, T., Ye, J., Faircloth, B.C., Remm, M. and Rozen, S.G., 2012. Primer3-new capabilities and interfaces. Nucleic acids research, 40(15), pp. e115-e115.

\section{How to cite this article:}

Deepthi, B., D. Ratnamma, R. N. Ramani Pushpa, Shrikrishna Isloor, B. M. Veeregowda and Satyanarayana, M. L. 2020. Molecular and Biological Characterization of a Vaccine - Derived Avian Avulavirus Type 1 Isolated from an Unvaccinated Goose. Int.J.Curr.Microbiol.App.Sci. 9(09): 277-285. doi: https://doi.org/10.20546/ijcmas.2020.909.035 